\title{
Bilateral pulmonary emboli after bilateral mastectomy in a 15-year-old boy with hypogonadism: A case report
}

\author{
JR Piggott BSc, Arjang Yazdani MD FRCSC
}

\begin{abstract}
JR Piggott, A Yazdani. Bilateral pulmonary emboli after bilateral mastectomy in a 15-year-old boy with hypogonadism: A case report. Can J Plast Surg 2010;18(4):e50-e52.

Pulmonary emboli are rare, yet serious, complications of body contouring surgery. When they occur, they more often follow as complications of long, invasive procedures in adults. The present report details a case of bilateral pulmonary emboli in an obese 15-year-old boy with hypogonadism undergoing bilateral mastectomy for gynecomastia. The diagnosis of bilateral pulmonary emboli was made on the basis of clinical presentation and positive ventilation/perfusion scan. The patient responded well to heparin anticoagulation treatment. The relevance of pediatric obesity, pediatric body contouring surgery and the risk of thromboembolic events in pediatric patients are discussed.
\end{abstract}

Key Words: Bilateral mastectomy; Gynecomastia; Hypogonadism; Obesity; Pulmonary emboli

\section{Une embolie pulmonaire bilatérale après une mastectomie bilatérale chez un garçon de 15 ans ayant un hypogonadisme : Rapport de cas}

\begin{abstract}
Les embolies pulmonaires sont des complications rares, mais graves, des chirurgies de la silhouette. Lorsqu'elles se produisent, elles constituent souvent des complications de longues interventions effractives effectuées chez des adultes. Le présent rapport détaille un cas d'embolie pulmonaire chez un garçon obèse de 15 ans ayant un hypogonadisme et qui a subi une mastectomie bilatérale en raison d'une gynécomastie. Le diagnostic d'embolie pulmonaire bilatérale a été posé d'après la présentation clinique et une scintigraphie pulmonaire de ventilation. Le patient a bien réagi au traitement anticoagulant à l'héparine. Les auteurs abordent la pertinence de l'obésité juvénile, la chirurgie de la silhouette en pédiatrie et le risque d'événements thromboemboliques chez des patients pédiatriques.
\end{abstract}

$\mathrm{T}$ he prevalence of adolescent obesity is on the rise, as are its associated complications and comorbidities (1-3). In 2004, nearly one-third of Canadian adolescents between 12 and 17 years of age were reported as being either overweight or obese - a figure that has nearly doubled since 1978 (4). Since the recognition of this ongoing increase, the health effects related to obesity in children and adolescents have been widely examined. Early-onset type 2 diabetes, breathing difficulties, hypertension, hyperlipidemia and nonalcoholic fatty liver disease have all been well established as health concerns for which the obese pediatric patient is at risk $(2,5,6)$.

It remains a question whether increased morbidity and mortality following surgical procedures is yet another health concern that is associated with adolescent obesity. In adults, obesity has been linked to increased perioperative and postoperative complications in a number of recent studies. High body mass index (BMI) has been associated with significant increases in complication rates following prostatectomy, kidney transplantation, colorectal surgery, hip arthroplasty and body contouring surgery, among others $(7-14)$. Despite this accepted association in adults, the relationship between pediatric obesity and complications following surgical procedures is only recently being considered.

It is not uncommon for obese adolescent males to exhibit some degree of breast development. In recent literature (15), an incidence of up to $65 \%$ was reported for gynecomastia in adolescent boys between 14 and 15 years of age. Although a majority of these cases in adolescents are considered to be either physiological gynecomastia (which often resolves as puberty continues) or pseudogynecomastia secondary to obesity, some cases of adolescent gynecomastia, particularly those in male adolescents with endocrine disorders, persist well into adulthood (16). Currently, the standard of treatment for unresolving gynecomastia is surgery $(17,18)$; bilateral mastectomy has been performed in adolescents as young as 13 years of age (19).

Although the risks of body contouring surgery have been well established in adults, there is little literature on the rates of these complications in adolescents (18,20-22). As rates of adolescent obesity continue to increase, understanding the risks of these complications in obese adolescents and how to best manage them, prevent them and identify pediatric patients at high risk for them is becoming of greater importance.

We report a case of bilateral pulmonary embolism in an obese 15-year-old boy with hypogonadism following bilateral mastectomy as treatment for gynecomastia.

\section{CASE PRESENTATION}

A 15-year-old boy with partial central hypogonadism and an incidental pituitary adenoma presented with a two-year history of unresolving Rohrich grade $1 \mathrm{~B}$ gynecomastia. His BMI was $35 \mathrm{~kg} / \mathrm{m}^{2}$, and he had a history of severe childhood asthma, attention-deficit hyperactivity disorder, depression and smoking. His medications included testosterone injections (1 mg intramuscularly once a month), methylphenidate (40 mg once a day), risperidone (3 mg at night) and Ventolin (GlaxoSmithKline Canada) (when necessary). Previous treatment for his gynecomastia included monthly testosterone injections; however, after six months of treatment, no change in breast size was noted. The

Victoria Hospital, London Health Sciences Centre, London, Ontario

Correspondence: Dr Arjang Yazdani, Victoria Hospital, London Health Sciences Centre, 800 Commissioners Road East, Room E2-214,

PO Box 5010, London, Ontario N6A 5W9. Telephone 519-685-8320, fax 519-695-8322, e-mail arjang.yazdani@lhsc.on.ca 
patient underwent bilateral subcutaneous mastectomies through a periareolar approach; surgical time was $30 \mathrm{~min}$. No compression stockings, heparin or other prophylactic anticoagulation treatments were given. The operation proceeded without complication; the patient's heart rate remained stable between 70 beats/min and 100 beats/min throughout the procedure. The patient recovered from anesthesia, and when alert, showed no signs of respiratory distress and was communicating comfortably. It was noted that the patient's oxygen saturations were decreasing slightly; a fraction of inspired oxygen of $40 \%$ was required to maintain an oxygen saturation of $94 \%$. As a result of his increasing oxygen requirements postoperatively, a ventilation/perfusion (V/Q) scan was obtained, and he was diagnosed as having a high probability for bilateral pulmonary emboli. He was started on intravenous heparin.

A coagulopathy screen was performed postoperatively to assess for hematological abnormalities; the international normalized ratio and the partial thromboplastin time were both in the normal range (1.1 and $27 \mathrm{~s}$, respectively), and no other measured values suggested any hematological abnormalities. A chest $\mathrm{x}$-ray performed the evening of the patient's surgery was normal. Bilateral Doppler ultrasound of his lower limbs was performed three days following his operation to assess for deep venous thromboses, which showed none. A cardiac assessment found no increase in right-sided pressures or right-sided strain pattern on electrocardiogram. The final diagnosis was bilateral pulmonary embolism without known embolic source.

\section{DISCUSSION}

Pulmonary emboli are rare, yet recognized, complications of body contouring surgery. In children and adolescents, the frequency of thromboembolic events, including pulmonary embolism, is much lower than in adults (23). A 15-year retrospective study by Bernstein et al (24) reported an incidence of 78 cases of thromboembolic complications per 100,000 hospitalized adolescents, compared with a reported incidence of between 119 and 900 cases per 100,000 hospitalized adults (25). As a consequence, pulmonary emboli are underdiagnosed in this population due, in large part, to their rarity and due to lack of clinical suspicion (23). Pulmonary embolism can be fatal if unrecognized, and thus the first step in management is rapid identification, followed by prompt anticoagulation treatment. Patients typically present with an acute decrease in the partial pressure of oxygen and symptoms of hemoptysis, dyspnea and chest pain, although asymptomatic and atypical presentations are quite common (24). A diagnosis of pulmonary embolism is made based on the patient's clinical pretest probability and on their results from further investigation: V/Q scan, D-dimer testing and chest $\mathrm{x}$-ray may all help in diagnosis (25). Our patient presented with a decrease in the partial pressure of oxygen and a positive $\mathrm{V} / \mathrm{Q}$ scan for pulmonary embolism, and was quickly diagnosed and treated appropriately, avoiding any devastating outcomes. The most common source of clinically relevant pulmonary embolism is deep venous thrombosis, arising most frequently from the iliac, popliteal or femoral veins, and thus a lower extremity venous ultrasound is commonly performed to check for deep venous thrombosis (25). In the case of our patient, whose ultrasound was negative for deep venous thrombosis, the source of his pulmonary emboli could not be identified. Other less common sources of deep venous thrombosis are the right heart and the renal and pelvic veins but, in children, it is common for the source to remain unknown (24). No reports are available on pulmonary emboli accompanying bilateral mastectomy in a pediatric patient.

As a specific complication of body contouring procedures, pulmonary emboli are often seen after long procedures such as abdominoplasty or liposuction (26-28). They are less commonly seen in mastectomy, yet are still recognized as known complications and have been reported (26). A retrospective study by Shermak et al (7) examining thromboembolic complications of body contouring surgery reported one case of pulmonary embolism in 188 patients. A BMI of greater than $35 \mathrm{~kg} / \mathrm{m}^{2}$ was the main risk factor for a thromboembolic event identified in patients undergoing body contouring procedures.

The frequency of body contouring procedures in the pediatric population is still relatively small and, thus, rates of pulmonary embolism as a complication of bilateral mastectomy in children are currently undocumented. What makes a patient susceptible to pulmonary embolism has been widely researched, but in children, it is still not well understood due to the rarity of this complication. Victoria et al (23) reported a higher incidence of recent surgery, blood dyscrasias and oral contraceptive use in pediatric patients presenting with pulmonary emboli. The general risk factors for thromboembolic events in adults, identified frequently in the literature as venostasis, hypercoagulability, vessel wall inflammation (Virchow's triad), recent surgery or trauma, and malignancy, can be applied to children as well. Other risk factors such as obesity, smoking, estrogen therapy, prolonged bed rest, inherited disorders of coagulation and previous pulmonary embolism are also well accepted in the literature as known risk factors for thromboembolic complications. In addition, hypogonadism, risperidone and testosterone injections have also been shown to correlate with the incidence of deep venous thrombosis and pulmonary embolism in a small number of studies $(7,21,24,25,27,29-31)$. Our patient was subject to many of these risk factors. It is possible that his combination of risk factors contributed to his complication.

Most notable of our patient's risk factors was his morbid obesity. Shermak et al (7) reported that $100 \%$ of the thromboembolic events occurring as complications of various body contouring procedures occurred in patients with a BMI of more than $35 \mathrm{~kg} / \mathrm{m}^{2}$. A chart review by Hatef et al (27) examining thromboembolic risk assessment in body contouring surgery procedures also noted BMI greater than $30 \mathrm{~kg} / \mathrm{m}^{2}$ to be a significant risk factor for thromboembolic complications. In most recent literature, when stratifying patients based on their level of risk, many studies have adopted this correlation between BMI and thromboembolic complications and include BMI as a predisposing factor in their scoring (32). Although no studies to date highlight a similar correlation in the pediatric population, it can be speculated that our patient's morbid obesity contributed to his complication. Shermak et al (7) recommended that patients at higher risk for thromboembolic complications be treated with a high dose of heparin postoperatively, and continue on low-molecular weight heparin for two weeks following surgery.

In addition to obesity, our patient had a history of smoking - a habit currently considered to be an independent risk factor for thromboembolic events (29). Several studies have indicated a 
connection between hypogonadism in men and thromboembolic tendencies. A study by Bennet et al (30) suggested a correlation among hypogonadism, defective fibrinolysis and deep venous thrombosis, and found that fibrinolytic activity in response to venous occlusion was abnormal in men with hypogonadism compared with controls. A separate set of studies $(21,31)$ have also linked risperidone treatment to thromboembolic events. Cases of pulmonary emboli and thromboembolic events have been reported in patients treated with risperidone who possess no other risk factors $(21,31)$. A study by Kamijo et al (31) proposed that the affinity of risperidone for the serotonin receptor may increase coagulability in these patients. Our patient was receiving risperidone treatment for his depression and disruptive behaviour up until the date of his surgery; thus, risperidone may also have played a role in his complication.

Recent recommendations from several studies support the treatment of patients at high risk for thromboembolism with prophylactic anticoagulation therapy. A large study by Miszkiewicz et al (26), which examined recommendations in the literature for thromboembolism prophylaxis in plastic surgery, found that a considerable majority ( 24 of 27 studies) were in favour of prophylactic procedures. A study by Seruya et al (32)

\section{REFERENCES}

1. Ogden CL, Flegal KM, Carroll MD, Johnson CL. Prevalence and trends in overweight among US children and adolescents, 1999-2000. JAMA 2002;288:1728-32.

2. Sabin MA, Shield JP. Childhood obesity. Front Horm Res 2008;36:85-96.

3. Health Canada. <http://www.hc-sc.gc.ca/hl-vs/pubs/child-enfant/ advisor-conseillere/obesit-eng.php> (Accessed on April 2009).

4. Statistics Canada. <http://www.statcan.gc.ca/pub/82-620-m/2005001/ article/child-enfant/8061-eng.htm> (Accessed on April 2009).

5. Lavine JE, Schwimmer JB. Nonalcoholic fatty liver disease in the pediatric population. Clin Licer Dis 2004;8:549-58.

6. Spiotta RT, Luma GB. Evaluating obesity and cardiovascular risk factors in children and adolescents. Am Fam Physician 2008;78:1052-8.

7. Shermak MA, Chang DC, Heller J. Factors affecting thromboembolism after bariatric body contouring surgery. Plast Reconstr Surg 2007;5:1590-6.

8. Herman MP, Raman JD, Dong S, Samadi D, Scherr DS. Increasing body mass index negatively impacts outcomes following robotic radical prostatectomy. JSLS 2007;11:438-42.

9. Castle EP, Atug F, Woods M, Thomas R, Davis R. Impact of body mass index on outcomes after robot assisted radical prostatectomy. World J Urol 2007;26:91-5.

10. Cacciola RA, Pujar K, Ilham MA, Puliatti C, Asderakis A, Chavez R. Effect of degree of obesity on renal transplant outcome. Transplant Proc 2008;40:3408-12.

11. Chang SH, Coates PT, McDonald SP. Effects of body mass index at transplant on outcomes of kidney transplantation. Transplantation 2007;84:981-7.

12. Pikarsky AJ, Saida Y, Yamaguchi T, et al. Is obesity a high-risk factor for laparoscopic colorectal surgery? Surg Endosc 2002;16:855-8.

13. Merkow RP, Bilimoria KY, McCarter MD, Bentrem DJ. Effect of body mass index on short-term outcomes after colectomy for cancer. J Am Coll Surg 2008;208:53-1.

14. Lubbeke A, Moons KG, Garavaglia G, Hoffmever P. Outcomes of obese and nonobese patients undergoing revision total hip arthroplasty. Arthritis Rheum 2008;59:738-45.

15. Davanco RA, Sabino Neto M, Garcia EB, Matsuoka PK, Huijsmans JP, Ferreira LM. Quality of life in the surgical treatment of gynecomastia. Aesthetic Plast Surg 2008;33:514-7.

16. Ma NS, Geffner ME. Gynecomastia in prepubertal and pubertal men. Curr Opin Pediatr 2008;20:465-70.

17. Colombo-Benkmann M, Buse B, Stern J, Herfarth C. Indications for and results of surgical therapy for male gynecomastia. Am J Surg 1999;178:60. suggested the use of both mechanical prophylaxis (graduated compression stockings) and low-molecular weight heparin for high-risk patients undergoing planned body contouring surgery to prevent deep vein thrombosis and pulmonary embolism. These strategies are in agreement with the prophylactic algorithm suggested by Abs (33) who agreed that, along with early mobilization, low-molecular weight heparin and compression stockings should be used. Surveillance investigation of the lower limbs for deep vein thrombosis in high-risk patients is also recommended to prevent progression to pulmonary embolism (33).

\section{CONCLUSION}

We encountered an unexpected complication of bilateral pulmonary emboli in an obese adolescent patient following bilateral mastectomy, which may have been due to a variety of factors that increased this patient's thrombotic tendency. The ongoing increase in pediatric obesity, when considered with both the high rate of mortality associated with pulmonary embolism and the multitude of risk factors that may present in an adolescent, emphasizes the need for further understanding of the risks of body contouring surgery in adolescents.

18. Gabra HO, Morabito A, Bianchi A, Bowen J. Gynaecomastia in the adolescent: A surgically relevant condition. Eur J Pediatr Surg 2004;14:3-6.

19. Handschin AE, Bietry D, Hüsler R, Banic A, Constantinescu M. Surgical management of gynecomastia - a 10-year analysis. World J Surg 2008;32:38-44.

20. Lanitis S, Starren E, Read J, et al. Surgical management of gynaecomastia: Outcomes from our experience. Breast 2008; 17:596-603.

21. Borras L, Eytan A, De Timary P, Constant EL, Huguelet P, Hermans C. Pulmonary thromboembolism associated with olanzapine and risperidone. J Emerg Med 2008;2:159-61.

22. Steele SR, Martin MJ, Place RJ. Gynecomastia: Complications of the subcutaneous mastectomy. Am Surg 2002;68:210.

23. Victoria T, Mong A, Altes T, et al. Evaluation of pulmonary embolism in a pediatric population with high clinical suspicion. Pediatr Radiol 2008;1:35-41.

24. Bernstein D, Coupey S, Schonberg SK. Pulmonary embolism in adolescents. Am J Dis Child 1986;140:667-71.

25. Ramzi DW, Leeper KV. DVT and pulmonary embolism: Part 1. Diagnosis. Am Fam Phys 2004;69:12.

26. Miszkiewicz K, Perreault I, Landes G, et al. Venous thromboembolism in plastic surgery: Incidence, current practice and recommendations. J Plast Reconstr Aesthet Surg 2009;62:580-8.

27. Hatef DA, Kenkel JM, Nguyen MQ, et al. Thromboembolic risk assessment and the efficacy of enoxaparin prophylaxis in excisional body contouring surgery. Plast Reconstr Surg 2008;122:269-79.

28. Davison SP, Venturi ML, Attinger CE, Baker SB, Spear SL. Prevention of venous thromboembolism in the plastic surgery patient. Plast Reconstr Surg 2004;114:43E-51E.

29. Petitti DB, Wingerd J, Pellegrin F, Ramcharan S. Oral contraceptives, smoking, and other factors in relation to risk of venous thombolic disease. Am J Epidemiol 1978;6:480-5.

30. Bennet A, Sie P, Caron P, et al. Plasma fibrinolytic activity in a group of hypogonadic men. Scand J Clin Lab Invest 1987;1:23-7.

31. Kamijo Y, Soma K, Nagai T, Kurihara K, Ohwada T. Acute massive pulmonary thromboembolism associated with risperidone and conventional phenothiazines. Circ J 2003;1:46-8.

32. Seruya M, Venturi ML, Iorio ML, Davison SP. Efficacy and safety of venous thromboembolism prophylaxis in highest risk plastic surgery patients. Plast Reconstr Surg 2008;112:1701-8.

33. Abs R. Thromboembolism in plastic surgery: Review of the literature and proposal of a prophylaxis algorithm. Ann Chir Plast Esthet 2000;6:604-9. 